\title{
How Covid-19 has exposed inequalities in the UK food system:
}

\section{The case of UK food and poverty [version 1; peer review: 3}

\section{approved, 2 approved with reservations]}

\author{
Maddy Power (D1), Bob Doherty (iD)2, Katie J. Pybus', Kate E. Pickett ${ }^{1}$ \\ ${ }^{1}$ Health Sciences, University of York, York, Yorkshire, YO10 5GD, United Kingdom \\ ${ }^{2}$ The York Management School, University of York, York, Yorkshire, YO10 5GD, United Kingdom
}

\author{
V1 First published: 03 Apr 2020, 2:11 \\ https://doi.org/10.35241/emeraldopenres.13539.1 \\ Latest published: 13 May 2020, 2:11 \\ https://doi.org/10.35241/emeraldopenres.13539.2
}

\section{Abstract}

This article draws upon our unique perspective as academicpractitioners working in the fields of food insecurity, food systems, and inequality to comment on the empirical and ethical implications of Covid-19 for socio-economic inequalities in access to food in the UK. The Covid-19 pandemic has revealed the profound insecurity of large segments of the UK population; increased unemployment, reduced hours, and enforced self-isolation for multiple vulnerable groups is likely to lead to an increase in UK food insecurity, exacerbating dietrelated health inequalities. The social and economic crisis associated with the pandemic has exposed the fragility of the system of food charity which, at present, is a key response to growing poverty. A vulnerable food system, with just-in-time supply chains, has been challenged by stockpiling. Resultant food supply issues at food banks, alongside rapidly increasing demand and reduced volunteer numbers, has undermined many food charities, especially independent food banks. In the light of this analysis, we make a series of recommendations for social security policy, 'emergency' food provision, and retailers. We call for an immediate end to the five week wait for Universal Credit and cash grants for low income households. We ask central and local government to recognise that many food aid providers are already at capacity and unable to adopt additional responsibilities. We urge supermarkets to commit to paying their employees the Real Living Wage to mitigate against food insecurity amongst their staff now and in the future. The government's -impressive -- response to the economic crisis associated with Covid-19 has underscored a key principle: it is the government's responsibility to protect population health, to guarantee household incomes, and to safeguard the economy. Millions of households were in poverty before the pandemic, and millions more will be so unless the government continues to protect household incomes through policy change.
Open Peer Review

$\begin{array}{rrrrr}\text { Approval Status } & \checkmark \checkmark \checkmark \checkmark \checkmark \\ 1 & 2 & 3 & 4 & 5\end{array}$

version 2

(revision)

13 May 2020

version 1

03 Apr 2020
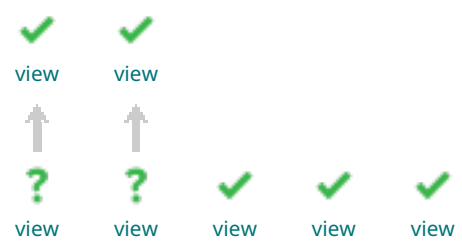

1. Peter Jackson (iD), University of Sheffield,

Sheffield, United Kingdom

2. Rachel Loopstra, King's College London, London, United Kingdom

3. Alex Murdock, London South Bank University, London, United Kingdom

4. Diane Holt ID, University of Leeds, Leeds, United Kingdom

5. Andrew Williams ID, Cardiff University, Cardiff, United Kingdom

Any reports and responses or comments on the article can be found at the end of the article. 


\section{Keywords}

food insecurity, food banks, food supply, inequality, poverty, Covid-19,

coronavirus, pandemic

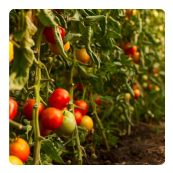

This article is included in the Sustainable Food

Systems gateway.

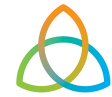

This article is included in the N8 AgriFood

N8 AgriFood

collection.

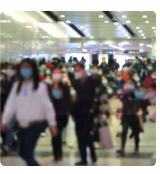

This article is included in the Coronavirus

(COVID-19) collection.

Corresponding author: Bob Doherty (bob.doherty@york.ac.uk)

Author roles: Power M: Writing - Review \& Editing; Doherty B: Writing - Review \& Editing; Pybus KJ: Writing - Review \& Editing; Pickett KE: Writing - Review \& Editing

Competing interests: Madeleine Power is Co-Chair of the Independent Food Aid Network (IFAN). The views expressed in this article are those of the author only; they do not necessarily represent the views of IFAN.

Grant information: This work was supported by the Biotechnology and Biological Sciences Research Council [BB/N02060X/1]. The authors gratefully acknowledge the funding from the Global Food Security Fund for the large programme grant titled, IKnowFood: Integrating Knowledge for Food Systems Resilience. IKnowFood was born out of the N8 Agrifood programme.

The funders had no role in study design, data collection and analysis, decision to publish, or preparation of the manuscript.

Copyright: @ 2020 Power $\mathrm{M}$ et al. This is an open access article distributed under the terms of the Creative Commons Attribution License , which permits unrestricted use, distribution, and reproduction in any medium, provided the original work is properly cited.

How to cite this article: Power M, Doherty B, Pybus KJ and Pickett KE. How Covid-19 has exposed inequalities in the UK food system: The case of UK food and poverty [version 1; peer review: 3 approved, 2 approved with reservations] Emerald Open Research 2020,

2:11 https://doi.org/10.35241/emeraldopenres.13539.1

First published: 03 Apr 2020, 2:11 https://doi.org/10.35241/emeraldopenres.13539.1 


\section{Background: A fragile just-in-time food system and rising food insecurity}

The Covid-19 pandemic, and associated pressures on food access, have revealed stark inequalities in the UK system of food supply and food distribution. During extreme scenarios such as this, consumers sometimes demonstrate purchasing behaviours to mitigate against the risk of not being able to purchase food, or indeed other items, at a later date (Slonim \& Garbarino, 2009; Sterman \& Dogan, 2015) -- for example, in recent weeks we have seen evidence of stockpiling, hoarding, and panic buying. Stockpiling is an accumulation of goods predominantly motivated by a desire to minimise the loss of, or the risk of losing access to certain products, and may arise due to a belief that a product is in short supply, will soon no longer be available, or that its price is likely to increase. In the UK, this has led to panic buying and empty shelves in supermarkets, jeopardising the food security of more vulnerable groups. According to the British Retail Consortium (BRC), the recent demand spike has exceeded what is forecasted for peak periods such as Christmas (BRC, 2020a), whilst, in contrast, other affected countries such as Italy have seen limited panic buying (Sky News, 2020).

The situation has exposed the vulnerabilities embedded within the UK food system and our dependence on just-in-time (JIT) supply chains, which operate to source produce at competitive prices from overseas territories in a quick and efficient manner. It is widely known that the UK imports $48 \%$ of its food -- in fact, for fresh fruit it is $84 \%$ and for vegetables $46 \%$ (ONS, 2018). It is also important to note that the UK is heavily reliant on EU countries, such as Spain for vegetables and salads and Italy for ambient goods, for instance, tinned tomatoes and pasta. However, despite these advances in supply chain technology and logistics, this increased sourcing efficiency has paradoxically made supply chains more vulnerable to disruptions. Approaches including 'lean sourcing', JIT systems, standardised components, and reductions in the supply base have tended to neglect the systemic risks caused by exogenous shocks or disruptions to the supply chain (Christopher \& Peck, 2004; Lee \& Rammohan, 2017). Covid-19 is testing food supply chains to their limits and yet, according to the UK Government, we are in the early stages of the pandemic, in terms of its direct and indirect health, economic and social impacts. This demand-led behaviour has caused empty shelves; only in recent days have some supermarkets placed restrictions on purchase volumes.

Heightened vulnerabilities within our food system exposed by the economic and social crisis associated with the Covid-19 pandemic occur against a backdrop of growing inequalities in access to food in the UK. These inequalities divide households and individuals who have adequate income, mobility and social support to be able to access food through 'normal' channels -- purchasing fresh or prepared produce at shops, cafes and restaurants -- from those who do not (Garthwaite, 2016; Lambie-Mumford, 2017; Loopstra et al., 2015). Between April 2018 and March 2019, the Trussell Trust's network of food banks distributed 1.6 million food parcels, a 26-fold increase on 2010 (Trussell Trust, 2019a). Trussell Trust food banks represent approximately two thirds of all food banks operating in the UK -- there are over
800 food parcel distribution projects or food banks operating outside of the Trussell Trust's network of food banks (Loopstra et al., 2019) -- and, hence, their statistics underestimate food bank use. Across Scotland, between April 2017 and September 2018, 221,977 food parcels were distributed by 84 independent food banks, roughly equivalent to the 258,606 food parcels distributed by Trussell Trust food banks (Goodwin, 2018).

Furthermore, the number of households who have 'limited access to food' due to 'lack of money or financial resources' (food insecurity) (FAO, 2017) is poorly reflected in statistics on food bank use. The Food Standards Agency (FSA, 2017) estimates that $13 \%$ of UK adults are 'marginally food insecure' and $8 \%$ are moderately or severely food insecure. The variation between the extent of food bank use and the prevalence of food insecurity can be sharply captured at the local level: in York, for example, only $20 \%$ of households reporting food insecurity had ever used a food bank (Power, 2019).

The demography of food insecurity in the UK is unevenly distributed. It is particularly high among people who are unemployed (47\% of whom report food insecurity) and those in the lowest income quartile (34\%) (FSA, 2017). Women are more likely to live in food insecure households than men (10\% compared to 6\%) and there is evidence that the likelihood of food insecurity varies by ethnic group (Power et al., 2018a). Poor diet and broader experiences of food insecurity are important factors in lower life-expectancy, weakened immunity (Health Foundation, 2020), and poorer mental health and wellbeing (Tarasuk et al., 2013). Food insecurity has long-term and life-changing consequences: it is highly associated with both malnutrition and obesity among adults and children (Martin \& Ferris, 2007); it compromises educational outcomes among children (Jyoti et al., 2005); and hinders stable employment among adults (Lent et al., 2009). Sustained and, particularly, hidden food insecurity is, thus, both an individual and a societal issue.

This article draws upon our unique perspective as academicpractitioners working in the field of food insecurity, food systems, and inequality to comment on the empirical and ethical implications of Covid-19 for socio-economic inequalities in access to food in the UK. Alongside roles as academics, Doherty and Pybus have policy experience; Power participates in a national network of food aid providers; Pickett and Power have experience working within charities. Pickett also has over twenty years of experience working in the field of inequalities. In the context of existing literature on food insecurity, food systems, and socio-economic inequalities, as well as our own body of research on inequalities in food access, we chronicle and assess the multiple inequalities exposed by Covid-19, in access to food; within the food aid sector; and between retailers and food aid providers.

This is an unprecedented health and economic crisis, with unpredictable and fast-moving events, accompanied by major policy changes. It is possible that the challenges, events, and policy changes documented in this article will become out-dated even in the short-term. However, we believe that the process of chronicling and reflecting upon events as they 
happen during the period of the pandemic is itself important in understanding how we, as a society, respond to major challenges and in considering how we can prevent the escalation of existing inequalities that may result from Covid-19. It is important to make clear that at no point are we under-estimating the tireless efforts of staff and volunteers in food banks and other charitable food aid providers in supporting those who lived in poverty before this crisis and will be pushed into poverty as a result of it. This paper is a consideration of inequality and poverty, and the charitable organisations that respond to it, in the context of wider structures and broader processes.

The paper is structured as follows. To begin, we consider the inequalities in income, diet, and access to food in the UK exposed by the social and economic crisis associated with Covid-19. This is followed by an assessment of the resilience -- and the uniformity of this resilience -- of the UK food banking system in the context of the pandemic. We discuss how Covid-19 has changed the relationship between supermarkets and food aid providers, and reflect upon political and ethical debates surrounding food charity in the UK that have been further illuminated by the pandemic. To conclude, we make a series of recommendations for social security policy, 'emergency' food provision, and supermarkets, and consider how the Covid-19 pandemic may and could change socio-economic inequalities in the UK.

\section{Commentary: multiple food inequalities in the context of Covid-19}

Inequalities in income, diet, and access to food

The social and economic fallout of Covid-19 has exposed the extreme precarity of large segments of the UK population. Food banks have seen sharp increases in demand for food due to sudden unemployment and reduced wages as organisations implement redundancies and scale down staffing (Cipriani, 2020). Panic buying, and consequent food shortages on supermarket shelves, has jeopardised the food security of low income households and individuals in vulnerable groups. Many low income households are financially unable to stockpile and, confronted with only the most expensive versions of products, cannot purchase adequate food. Our research on the lived experience of food on a low income shows the complicated food management and shopping strategies adopted by low income households to maintain food security, including buying reduced cost items and cheaper, own-brand products; shopping at multiple supermarkets to find the cheapest items; and budgeting on a long-term basis (Power et al., 2018b). Insecure employment and poor availability of food in supermarkets renders such strategies impossible, forcing households to access food from food banks or go without food entirely. In addition, recent figures produced by the Food Foundation, using government data, suggests that over 17 million people are in the higher risk category for coronavirus because they are elderly, have underlying health conditions, or are pregnant. At least 860,000 individuals in this category were struggling to purchase adequate food before the crisis and over 1 million of them, who report always or often being lonely, may struggle to find people to deliver food to them (Food Foundation, 2020). The virus is, thus, highly likely to increase the nutritional vulnerability of multiple already vulnerable groups, exacerbating diet-related inequalities. This may have short-term -- in particular weaker immunity and higher risk of Covid-19 -- and long-term consequences for health, wellbeing, and equity (Health Foundation, 2020).

The acceleration of Covid-19 has led to rapid changes in government policy, as employers across multiple sectors close premises to help slow the spread of the virus. Protections for some businesses and employees have now been outlined, but a delay between the announcement of social distancing measures, leading to closures, and the implementation of employee protection schemes has already precipitated redundancies. In addition, some companies have gone into administration while others, who do not qualify for Government grants, are at continued risk of doing so, or face mounting debts with potential consequences for jobs (Financial Times, 2020). Employees have, however, been offered a number of protections that may help to mitigate against loss of income (Department for Business, Energy and Industrial Strategy, 2020). These include being able to claim statutory sick pay from the first day of illness or self-isolation; the introduction of the Coronavirus Job Retention Scheme (CJRS), in which $80 \%$ of salary costs will be paid by the Government with an equivalent scheme for those who are self-employed; and increases to Universal Credit, albeit eligibility remains contingent upon overall household income. In addition to mortgage holidays and new rules on evictions in force for the next three months, these measures may mitigate against large scale income shocks amongst the majority of the population, so limiting the extent of increases in food insecurity.

Less clear, however, is the level of protection the measures will provide in the short- to medium- term. Employers, for example, are not required to fund the difference between salary costs paid by the Government under the retention scheme and the usual salary of the person (Department for Business, Energy and Industrial Strategy, 2020). This means that some households could see their income reduce by a fifth for a sustained period of time, during which costs for utilities and food may increase as a result of families staying at home. In addition, those on zero hours contracts are not entitled to be part of the CJRS and their continued receipt of wages is at the discretion of employers. Reduced incomes may be exacerbated by existing financial difficulties, for example, the Office for National Statistics (2018) estimates that two thirds of the poorest $40 \%$ of UK households have financial debts (excluding those relating to property).

Further support is being offered through the social security system. New and existing Universal Credit and Working Tax Credit claimants will see an increase in payments of $£ 20$ per week, and an assumed level of earnings used to calculate entitlement (the minimum income floor) has been removed for the self-employed (Department for Work and Pensions, 2020). Housing benefit will increase for all new and existing claimants to cover up to the 30th percentile of market rents (Department for Work and Pensions, 2020). However, there are currently no plans to reduce the five-week wait for Universal Credit, a key driver of income shocks associated with food insecurity (Trussell Trust, 2019b) and it is possible that waiting times for payments may increase further with the sudden, increased demands placed on the 
application system. This means that potentially large numbers of households will require advance payments and subsequently receive lower monthly amounts than their initial entitlement, with longer term implications for household incomes.

The measures to support households in these unprecedented and challenging circumstances are welcome and -- in the short term -- may assist in mitigating against a large-scale increase in poverty, including food poverty and insecurity. The longer-term implications are as yet uncertain. For the lowest income households, increases in Universal Credit, should these remain for the foreseeable future, may reduce risks of food insecurity. It is possible, however, that in the longer term, the pandemic could place higher numbers of households in precarious financial circumstances. The Joseph Rowntree Foundation (2020) has recommended additional social security protections including suspending all benefit deductions -- for example, utilities and debts to local councils for the next six months, extending the time period for repayment of Universal Credit advances, and increasing the child element of Universal Credit to enable families to pay for extra meals for children. It may be that already announced policy responses need to go further in the coming months.

\section{Emerging fragilities within the UK food aid system}

The social, economic and health crisis surrounding and stemming from Covid-19 has exposed the fragility of the system of 'emergency' food aid in the UK. Before the crisis, food banks (and other community food providers) largely received food in three ways: surplus food redistributed directly by supermarkets or indirectly by charities, such as FareShare; food donated by individuals either within the supermarket itself (for instance, in a donation basket), directly to the food bank, or through other charities/organisations (e.g. a local church); and food purchased in bulk by the food bank from local supermarkets and shops (see Table 1). The social and economic crisis surrounding Covid-19 has jeopardised these food supply chains. Individual food donations have dropped sharply as households prioritise their own food supply, while many food banks are unable to purchase the non-perishable items required for standard food parcels, due to supermarket rationing and the poor availability of much of this produce as a result of stockpiling (Butler, 2020).

Volunteers are integral to the provision of food charity in the UK. Between 2016 and 2017, volunteers contributed a total of $4,117,798$ hours of labour supporting food banks, including distributing and caring for service users within the food bank, stock-taking, fundraising, collecting and delivering food, and inputting data (IFAN, 2017). Before the pandemic, $75 \%$ of independent food banks relied on five or more volunteers each week (Loopstra et al., 2019). These volunteers tend to be older (over 70) and some have underlying health conditions; social distancing rules have caused many of these volunteers to stay away from food banks, placing considerable additional pressure on volunteers and staff continuing to distribute food. The 'lockdown' is likely to exacerbate pressures on staffing further.

In recent years, there has been a rise in food aid responses that specifically target families with children, in recognition of additional food costs and a need to ensure that children do not experience hunger -- for example, breakfast clubs and holiday hunger schemes (Garnham, 2020). The issues facing families are likely to be exacerbated by the closure of schools, a further necessity to reduce transmission of the virus. Children who have key workers as parents or who are defined as vulnerable, for example, looked after children and those with a child protection plan or special educational needs, will be able to remain in school but most children will now be unable to attend (Department for Education, 2020). Low income families with children who are eligible for free school meals will instead be provided with vouchers for local supermarkets, paid at a higher rate to reflect the increased costs attached to buying from supermarkets and the inability to purchase wholesale as schools do when providing these meals (Department for Education, 2020). How far these vouchers enable families to purchase nutritional meals will depend on the availability of supermarket food and the impact of stockpiling, but this response should, nevertheless, ensure that these

Table 1. Food supply systems to food banks.

\begin{tabular}{|l|l|l|}
\hline Food supply & Partners involved & Challenges posed by Covid-19 pandemic \\
\hline $\begin{array}{l}\text { Surplus and non-surplus food } \\
\text { direct from supermarkets } \\
\text { (national-level) }\end{array}$ & $\begin{array}{l}\text { Supermarkets, Fairshare, City } \\
\text { Harvest, The Felix Project, } \\
\text { The Bread and Butter Thing } \\
\text { (TBBT), food banks, and other } \\
\text { food aid providers }\end{array}$ & $\begin{array}{l}\text { Dependent on partnerships established prior to Covid-19; } \\
\text { immense logistical challenge of setting up new partnerships, } \\
\text { food supplies, and deliveries in short time period; dependent } \\
\text { on availability of supermarket produce in context of high } \\
\text { demand from customers }\end{array}$ \\
\hline $\begin{array}{l}\text { Surplus food direct from shops } \\
\text { (local-level) }\end{array}$ & $\begin{array}{l}\text { Supermarkets, retailers, food } \\
\text { banks, and other food aid } \\
\text { providers }\end{array}$ & $\begin{array}{l}\text { Lower availability of surplus food due to stockpiling; } \\
\text { dependent on availability of volunteer and non-volunteer } \\
\text { delivery staff; dependent on existing relationships, prior to } \\
\text { Covid-19 }\end{array}$ \\
\hline $\begin{array}{l}\text { Food donated by individuals in } \\
\text { supermarkets }\end{array}$ & Food banks & $\begin{array}{l}\text { Much reduced donations by individuals due to supermarket } \\
\text { rationing and individual self-stockpiling }\end{array}$ \\
\hline $\begin{array}{l}\text { Food purchased in bulk from } \\
\text { supermarkets/shops by food } \\
\text { banks }\end{array}$ & Food banks & $\begin{array}{l}\text { Supermarket rationing, and lower stock availability vastly } \\
\text { limits food parcel items that can be purchased }\end{array}$ \\
\hline
\end{tabular}


families are not disadvantaged in terms of diet. The social support attached to communal schemes such as breakfast clubs will, however, be inaccessible for the foreseeable future.

It is also likely that a considerable number of children will now meet eligibility criteria for free school meals as a result of rapid reductions in household incomes and clarity is required as to whether these families will be able to access the supermarket voucher scheme. Further information is also needed as to whether contingency schemes will continue to support families during the school holidays, given that emergency family food aid provision is likely to be disrupted and services may be unable to keep up with increased demand. Broader rises in poverty across the UK have the potential to make many more families food insecure.

\section{Changing relationships between retailers and food charity, and inequalities between food aid providers}

The Covid-19 pandemic has changed and sharpened the relationship between retailers and food aid providers, and exposed the reality of food insecurity in the UK: it is a question of the distribution of food supply, not necessarily food supply itself. Food worth £1billion that would be on supermarket shelves is now within households (British Retail Consortium, 2020a), while food banks struggle to access sufficient food supplies and food insecurity looks set to increase. Supermarkets have acted to address this inequality in food supply, ensuring designated shopping periods for vulnerable individuals and key workers, and expanding distribution of surplus and non-surplus food to food charities (British Retail Consortium, 2020b).

The high profile of the Trussell Trust as both a national organisation and a local food provider, coupled with food reserves and well-established links with supermarkets nationally and locally, has underpinned a dramatic increase in financial donations from retailers (and individuals) to the Trussell Trust and its network of food banks since the onset of Covid-19 in the UK. In conjunction with Fareshare, the Trussell Trust has received $£ 5$ million from their established charity partner, Asda (Trussell Trust, 2020a), while the John Lewis Partnership, has pledged $£ 75,000$ to the Trussell Trust, in the first instance (British Retail Consortium, 2020b). These initiatives will greatly enhance the resilience of the Trussell Trust during the pandemic. However, independent food banks have seen no equivalent size donations. Pressures on food supply chains, alongside increased demand and reduced volunteer numbers, has pushed some -- especially independent -- food banks to 'breaking point' and caused others to close entirely (Bulman, 2020).

It may be too early to unpick the relative experiences of Trussell Trust and independent food banks during this period -- and, indeed, there have been emerging reports of Trussell Trust food banks closing, suggesting similarities in experiences of the pandemic (Wood, 2020). Nevertheless, long-established relationships with supermarkets, including Asda and Tesco, appear to have supported Trussell Trust food supply chains in times of crisis (Trussell Trust, 2020a). Independent food aid providers have historically resisted these relationships with large retailers, due to ethical concerns about the corporatisation of food aid (Independent Food Aid Network, 2018), or have established relationships more informally and at a grass-roots level, rendering such supply chains vulnerable to disintegration.

\section{Political and ethical debates on food charity illuminated by Covid-19}

The fragility of UK food charity, exposed by the pandemic, alongside apparent inequality between food aid providers, has thrown into sharp relief the reality of food aid in the UK. Despite frequent discursive framing as an 'emergency' source of food, or 'emergency' service (Wells \& Caraher, 2014), many food banks have proved unreliable and fragile -- in terms of volunteers, food supply, and premises -- in the context of the health, economic and social crisis -- the 'emergency' -- of the Covid-19 pandemic. Food banks and food charities that have proved resilient tend to be those with strong corporate partnerships, raising questions about the importance of the corporatisation of food aid -- itself highly contentious (see Fisher, 2017; Riches, 2018) -- to the viability of food charity in the UK.

Referral systems, in which third-party agencies act as a 'gateway' to food banks by issuing a voucher that can be redeemed for a food parcel, have proved unviable in the context of increased demand, alongside the closure or partial shut down of many referral agents. The Trussell Trust operates on a referral-only model (Trussell Trust, 2020b), and 60\% of independent food banks require referrals from third-party agencies (Loopstra et al., 2019). As 'gateway' agencies reduce face-to-face service provision or close down entirely, a voucher system could become untenable. While an e-referral system may be a possible short-term response, this could be particularly problematic for vulnerable adults -- for example, those who are older or who have disabilities, who may not have access to telephone or online communication methods if they need to request this support. Maintaining a voucher system at the present time also has the potential to place further demands on health and social care services, many of which will be the only remaining providers available to make referrals. At the same time, the number of adults and households considered vulnerable may increase significantly in light of newly introduced self-isolation rules affecting at least 1.5 million people with pre-existing health conditions (Public Health England, 2020), in addition to older individuals and pregnant women.

Independent food banks, $40 \%$ of which operate on an openaccess basis, have received clients who were unable to access a Trussell Trust food bank voucher (the Trussell Trust continues to operate a referral system, shifting from paper to online and telephone referrals), placing an additional strain on services. There are important ethical questions about the distribution of food in the context of supply shortages that are yet to be subject to public discussion -- how is food bank entitlement changed in this context? Who should receive food -- individuals who are vulnerable and in self-isolation, or the 'traditional' food bank client: individuals and households in poverty? There is a growing body of literature on how food banks exacerbate and give material form to the discursive division of the 'deserving' and the 'undeserving' poor (May et al., 2019). The 'new' groups of (self-isolating) vulnerable 
individuals -- older adults, pregnant women, and those with preexisting health conditions -- who may be reliant on food banks in the immediate- and longer- term adds a new dimension to this debate. Are these individuals, whose need for food support is a product of demography and health status, more entitled to food than those whose use of the food bank is attributable to low/no income? Are these individuals, like those who used food banks before the crisis, also subject to a cap on the number of vouchers for food that can be received during a certain time period? Given the well-established link between poverty and poor mental and physical health (Health Foundation, 2020), can a clear distinction be made between individuals seeking food support due to income and those requesting assistance due to health?

Social distancing rules have transformed interactions within food banks: instead of being invited into a building, service users are given a pre-packed food bank parcel, often at the threshold or delivered directly to their home (Trussell Trust, 2020c). Care, sign-posting, and choice is removed from the interaction. This undermines the role of food banks in addressing social isolation and acting to prevent the reasons for food bank attendance -- the root causes of food insecurity -- through onward referral; it may also threaten the agency and dignity of service users. The prepackaged parcel of non-perishable food may not only undermine the health of service users, exacerbating diet related inequalities, but also erode cultural inclusivity and further exclude ethnic minority groups from food banks, so increasing income and health inequalities between ethnic groups (for an analysis of cultural exclusivity and food charity see Power et al., 2018a).

The difficulties experienced by food banks in responding to rising destitution and food insecurity during this period reignites debate as to whether charitable food aid is -- and can ever be -an acceptable and effective alternative to the state in responding to the basic needs of citizens (see, for example, Cloke et al., 2017; Dowler \& O'Connor, 2012; Lambie-Mumford \& Dowler, 2014; Power et al., 2017). Community response to the social and economic fallout of the virus has been impressive and swift: thousands of 'mutual aid' groups have been organised across the $\mathrm{UK}$, representing the pre-existence of mutuality at the local level and building further solidarity between community members. At the same time, however, vulnerabilities in the system of food aid and distribution have been sharply exposed by the additional pressures of escalating unemployment and a compromised food supply; there is growing concern that issues with food supply and access to food banks will leave many individuals without food entirely. Local Government Resilience Forums may be better placed than food banks to coordinate essential food distribution at a local level, however, limited knowledge about the scale of food aid provision locally and nationally, and poor understanding of the number and demography of food insecure households before this crisis may hinder effective government intervention. Food charities, already operating at capacity before the crisis, may not be well-placed to assist such government-organised food distribution.

\section{Recommendations}

The Covid-19 pandemic has revealed the profound insecurity of large segments of the UK population and exposed the fragility of the system of food charity that, at present, is a key response to such precarity. A vulnerable food system, with JIT supply chains, has been challenged by stockpiling and panic buying. Resultant food supply issues at food banks, alongside rapidly increasing demand, has undermined many food charities, especially independent food banks. The food aid system appears to be unable to cope when faced with a health and economic emergency. In the light of this analysis, we make a series of recommendations for social security policy, 'emergency' food provision, and retailers.

\section{Social security}

It is evident that households require higher and more secure incomes to avoid destitution in the immediate response to the pandemic (within three months of March 2020); in the mediumterm, while strict social distancing endures; and into the longer-term, during the aftermath of the pandemic. First and foremost, the Government must end the five week wait for Universal Credit and streamline the processing time. Reducing the time from application to receipt of first payment will ensure that fewer households are reliant on advance payments and therefore facing debt or a longer-term reduction in payments at a time when they may already be experiencing increased financial difficulties.

Job centre closures and increased application demand (over 400,000 in nine days at time of writing) means that the majority of new claimants are being directed to complete their Universal Credit application online; however, reports suggest significant queues of over 100,000 applicants to complete online identity verification processes (Proctor, 2020). This is leading to delayed claims, and it is likely that the situation will worsen as more people apply over the coming weeks. A planned increase in the Department for Work and Pensions workforce (Department for Work and Pensions, 2020) may assist in reducing some of the pressures but immediate responses are also needed to ensure people are able to access social security support as quickly as possible. Removing the requirement for the new claim interview (previously face to face but now taking place by telephone) will expedite the claims process by preventing further delays in light of such sharp increases in demand. This interview is primarily arranged so that the claimant commitment can be signed and work search requirements set out, arguably, the need for either of these is redundant under the current economic circumstances.

We echo the Joseph Rowntree Foundation's (2020) call for further social security protections including suspending all benefit deductions for the next six months, increasing the child element of Universal Credit, and suspending the two child limit. In addition, we support the Child Poverty Action Group's recommendation to add $£ 10$ per week to child benefits. This would reduce child poverty by up to $5 \%$ and have a greater impact than the recently announced increases to Universal Credit and tax credits (CPAG, 2020). We urge the government to consider other mechanisms to maximise household financial resilience, for example, by capping or freezing utility bills.

The pandemic has further highlighted the well-documented financial disadvantages of people employed on zero hours contracts, in terms of both income and job security. These employees 
lack access to adequate income protection during the current crisis, as well as any guarantee of future continued employment. These are issues that could have been remedied by improvements to employer practices in the period preceding the crisis. In the aftermath of Covid-19, it will be important to query the extent to which it is acceptable that the state has protected the viability of many businesses who themselves continue to uphold employment practices that disadvantage large numbers of their staff.

\section{'Emergency' food provision}

Covid-19 has exposed the fragility of the food banking system. Food banks and other food aid providers are already at capacity and will struggle to adopt any additional responsibility required of them by central and/or local government. We recommend that households are given cash grants to enable them to buy the food they require, rather than food itself. It may be possible to administer this through hardship funds administered by local authorities, although these funds would need to increase substantially for this to be viable.

\section{Retailers/supermarkets}

Supermarkets are currently experiencing increased sales and enhanced profits, while their staff are working under extreme pressure. We recommend that supermarket employees are paid the Real Living Wage, which will increase household income and reduce food insecurity amongst this group. In addition, we recommend that retailers take an active role in promoting the health of all their customers, for instance, this may involve introducing promotions on fresh fruit and vegetables, to enable customers to improve the quality of their diet. Supermarkets could work to assist vulnerable groups and those on a low income with the price of a basket of goods, including by providing vouchers or a card which could be redeemed for certain produce (emulating Healthy Start for pregnant mothers and those with young children (Healthy Start, 2020). A number of supermarkets have responded quickly, by employing new staff from sectors such as hospitality. In addition, some supermarkets have also pledged food donations to both the Trussell Trust and FairShare networks and this should continue.

\section{Conclusions}

The government's response to the economic crisis associated with Covid-19 has been impressive. The "self-employed incomesupport scheme" completes an unprecedented response package for workers, alongside the earlier "job retention scheme" for employees. Together, the two schemes protect up to $80 \%$ of individual average earnings or profits for those eligible for up to three months, and at a cost of many tens of billions. The $£ 20$ a week ( $£ 1,000$ a year) increase in the value of Universal Credit, taking it to its highest real-terms value ever, after two decades of stagnation or declining value, will boost the incomes of millions of households. These policy changes have shown what is possible, and have underscored a key principle: ultimately, it is the government's responsibility to protect population health, to guarantee household incomes, and to safeguard the economy. Millions of households were in poverty before the pandemic, and millions more will be so unless the government continues to protect household incomes through additional policy change. It is wellestablished that food banks -- whether independent or affiliated with the Trussell Trust -- and other food aid providers are unable to improve household incomes and mitigate against food insecurity in the long-run. At present, they are fighting on all fronts but, ultimately, struggling in the face of this health and economic crisis.

\section{Data availability}

No data are associated with this article.

\section{Acknowledgements}

We are grateful to Jane Gulec for her assistance with the article. We would also like to thank all those working in food banks and other charitable food aid providers, who strive to provide people with food in these unprecedented and immensely difficult times.
Butler P: Food banks ask UK supermarkets to set aside coronavirus supplies. The Guardian. 2020. Reference Source

Bulman M: Coronavirus: Food banks forced to close amid Covid-19 outbreak. The Independent. 2020.

Reference Source

British Retail Consortium: Speech by Helen Dickinson (British Retail

Consortium CEO). Government Daily COVID-19 Briefing to the Nation, 21st March 2020, 2020a.

British Retail Consortium: Coronavirus: Latest Retailer Announcements. British Retail Consortium. 2020b.

Reference Source

Child Poverty Action Group: Child poverty continues to rise as pandemic response falls short for families. Child Poverty Action Group, 2020.

Reference Source

Cloke P, May J, Williams A: The geographies of food banks in the meantime. Progr Hum Geog. 2017; 41(6): 703-26.

Publisher Full Text
Cipriani V: Charities warn Covid-19 will hit vulnerable as some foodbanks struggle for supplies. Civil Society News, 2020. Reference Source

Department for Business, Energy and Industrial Strategy: CoVID-19: Guidance for employees. Department for Business, Energy and Industrial Strategy, 2020 Reference Source

Department for Education: Closure of educational settings: information for parents and carers. Department for Education, 2020.

Reference Source

Department for Work and Pensions: Coronavirus and claiming benefits. Department for Work and Pensions, 2020.

Reference Source

Dowler A, O'Connor D: Rights-based approaches to addressing food poverty and food insecurity in Ireland and UK. Soc Sci Med. 2012; 74(1): 44-51. PubMed Abstract | Publisher Full Text

Christopher M, Peck H: Building the resilient supply chain. Int $J$ Logist Manag. 2004; 15(2): 1-14

Publisher Full Text 
FAO, IFAD, WFP \& WHO: The State of Food Security and Nutrition in the World 2017. FAO, Rome, 2017.

Reference Source

Financial Times: UK entrepreneurs count the cost of coronavirus. Financial Times, 2020

Reference Source

Fisher A: Big hunger: The unholy alliance between corporate america and anti-hunger groups. Cambridge, MA: MIT Press, 2017.

Reference Source

Food Foundation: Covid-19: latest impact on food, 2020, Food Foundation. 2020.

Reference Source

FSA: The 'Food and You' survey Wave 4 (2016) in The 'Food and You' survey. Food Standards Agency: London. 2017; 1-87.

Reference Source

Garnham A: Is Food the Right Response to Child Hunger? Child Poverty Action Group, 2020

Reference Source

Garthwaite K: Hunger Pains. Bristol: Policy Press, 2016.

Goodwin S: Emergency Food Parcel Provision in Scotland April 2017 to September 2018. Independent Food Aid Network and Menu for Change, 2018. Reference Source

Health Foundation: Health Equity in England: The Marmot Review 10 Years On. 2020; London: Health Foundation and UCL Institute of Health.

Reference Source

Healthy Start. 2020

Reference Source

Independent Food Aid Network: IFAN's statement on the $£ 20$ million partnership between ASDA, FareShare and the Trussell Trust, Independent Food Aid Network. 2018

IFAN: Food Bank Volunteer Hours Research. The Independent Food Aid Network, 2017.

Reference Source

Joseph Rowntree Foundation: Three things our social security must do to keep people afloat. 2020

Reference Source.

Jyoti DF, Frongillo EA, Jones SJ: Food insecurity affects school children's academic performance, weight gain, and social skills. J Nutr. 2005; 135(12): 2831-2839.

PubMed Abstract | Publisher Full Text

Lambie-Mumford H, Dowler E: Rising use of "food aid" in the United Kingdom. Brit Food J. 2014: 116(9): 1418-1425.

Publisher Full Text

Lambie-Mumford $\mathrm{H}$ : Hungry Britain: The rise of food charity. Bristol: Policy

Press, 2017; 192

Reference Source

Lee HL, Rammohan SV: Improving social and environmental performance in global supply chains. Sustainable Supply Chains. Part of the Springer Series in Supply Chain Management book series. Switzerland, 2017: 4: 439-464. Publisher Full Text

Lent MD, Petrovic LE, Swanson JA, et al.: Maternal mental health and the persistence of food insecurity in poor rural families. $J$ Health Care Poor Underserved. 2009; 20(3): 645-661.

PubMed Abstract | Publisher Full Text

Loopstra R, Reeves A, Taylor-Robinson D, et al:: Austerity, sanctions, and the rise of food banks in the UK. BMJ. 2015; 350: h1775.

PubMed Abstract | Publisher Full Text

Loopstra R, Goodwin S, Goldberg B, et al:: A survey of food banks operating independently of The Trussell Trust food bank network. 2019

Reference Source

Martin K, Ferris AM: Food insecurity and gender are risk factors for obesity.

J Nutr Educ Behav. 2007; 39(1): 31-36.

PubMed Abstract | Publisher Full Tex
May J, Williams A, Cloke P, et al:: Welfare Convergence, Bureaucracy, and Moral Distancing at the Food Bank. Antipode. 2019; 51(4): 1251-1275.

Publisher Full Text

Office National Statistics: Horticulture statistics 2017 dataset. Defra. 2018.

Reference Source

Office for National Statistics: Household debt in Great Britain: April 2016 to

March 2018. 2018.

Reference Source

Power MS: Seeking justice: how to understand and end food poverty in York

York Food Justice Alliance, York, 2019

Reference Source

Power M, Small N, Doherty B, et al.: Hidden hunger? Experiences of food insecurity amongst Pakistani and white British women. Brit Food J. 2018b; 120(11): 2716-2732.

PubMed Abstract | Publisher Full Text | Free Full Text

Power M, Uphoff EP, Stewart-Knox B, et al.: Food insecurity and socio-

demographic characteristics in two UK ethnic groups: an analysis of women in the Born in Bradford cohort. J Public Health (Oxf). 2018a; 40(1): 32-40.

PubMed Abstract | Publisher Full Text

Power M, Doherty B, Small N, et al.: All in it together? Community food aid in a multi-ethnic context. J Soc Policy. 2017; 46(3), 447-471.

Publisher Full Text

Proctor K: Almost 500,000 people in UK apply for Universal Credit in nine days. The Guardian. 2020

Reference Source

Public Health England: Guidance on social distancing for everyone in the UK. 2020.

Reference Source

Riches G: Food Bank Nations: poverty, corporate charity and the right to food. Routledge, Oxon, 2018

Reference Source

Sky News: Coronavirus: What is it like on Rome's Empty Streets. 2020

Reference Source

Slonim R, Garbarino E: Similarities and Differences between Stockpiling and

Reference Effects. Manage Decis Econ. 2009; 30(6): 351-371.

Publisher Full Text

Sterman JD, Dogan G: "I'm not hoarding, I'm just stocking up before the hoarders get here.": Behavioral causes of phantom ordering in supply chains.

J Oper Manag. 2015; 39-40: 6-22.

Publisher Full Text

Tarasuk V, Mitchell A, McLaren L, et al.: Chronic physical and mental health conditions among adults may increase vulnerability to household food

insecurity. J Nutr. 2013; 143(11): 1785-93.

PubMed Abstract | Publisher Full Text

Trussell Trust: Asda donates $£ 5 \mathrm{~m}$ to food banks \& community charities to help people through COVID-19. 2020a.

Reference Sourc

Trussell Trust: Food Vouchers, Trussell Trust. 2020b.

Reference Source

Trussell Trust: Urgent request for support from churches. 2020c.

Reference Source

Trussell Trust: Record $1.6 \mathrm{~m}$ food bank parcels given to people in past year as the Trussell Trust calls for end to Universal Credit five week wait. Trussell Trust: London. 2019a.

Reference Source

Trussell Trust: Early Warning: Universal Credit and Food banks. 2019b. Reference Source

Wells R, Caraher M: UK print media coverage of the food bank phenomenon: from food welfare to food charity? Brit Food J. 2014; 116(9): 1426-1445. Publisher Full Text

Wood V: Coronavirus: Food banks strained as volunteers isolate and demand surges during pandemic, The Independent. 2020

Reference Source 


\section{Open Peer Review}

\section{Current Peer Review Status:

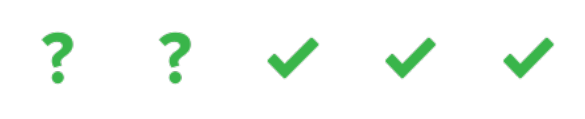

Version 1

Reviewer Report 20 April 2020

https://doi.org/10.21956/emeraldopenres.14610.r26711

(C) 2020 Williams A. This is an open access peer review report distributed under the terms of the Creative Commons Attribution License, which permits unrestricted use, distribution, and reproduction in any medium, provided the original work is properly cited.

\section{Andrew Williams}

School of Geography and Planning, Cardiff University, Cardiff, United Kingdom

Overall, this is a well written paper which documents the immediate challenges facing, and inequalities underpinning, the UK food system in the early stages of the COVID19 pandemic. Writing as the events unfold is valuable for future research as it provides a critical snapshot at the start of the pandemic. To this end, the paper will be a useful reference point as the assortment of government, business, and civil society responses evolve over time.

I have a few suggestions which the authors may wish to consider in their revisions of the article.

Firstly, the role of austerity is a major absence and it seems important to include this if we are to understand the uneven capacity of local government responses to COVID19 and food insecurity. The revised paper might also include a critical discussion of government food aid for people who are deemed 'clinically vulnerable' and need to be shielded. The nutritional quality and contents of the food parcels are considerably variable across local authorities. Yet most of these parcels seem to mirror the tinned and ambient items in a foodbank parcel (with a miserly portion of fresh veg and fruit). Why? There is also emerging evidence of local authorities adopting their own schemes such as cash payments to households eligible for free school meals rather than issuing supermarket vouchers (for example, Rhondda Cynon Taf weekly payment of $£ 19.50$ ).

Secondly, the paper is good at highlighting challenges facing the UK food aid sector, but an updated paper could offer an updated commentary on some of the organisational 'fixes' which have been developed by government, business and civil society as a response to these challenges. At times the position of the article is rather ambiguous. It critiques the corporatisation of food charity (page 6) then states, 'supermarkets have pledged food donations to both the Trussell Trust and FairShare networks and this should continue' (page 8). Alongside tightening the argument, I would invite the authors to offer their reflections on the ways the 'emergency' led to a contestation of radical and pragmatic sensibilities. What might be the long-term implications of the current response to COVID19 on the food aid sector? (NB: spelling FareShare).

Thirdly, a more variegated account of the food bank response is needed. The paper states ' $40 \%$ of 
[independents foodbanks] which operate on an open-access basis'. This needs a citation (Loopstra et al 2019) and a caveat about assessments and restrictions made by independent foodbanks to avoid a view that $40 \%$ independent foodbanks operate unlimited and direct access. The paper claims that referral agencies to foodbanks 'have proved unviable in the context of increased demand, alongside the closure or partial shut down of many referral agents.' Later the paper acknowledges how referral systems have increasingly utilised electronic / telephone referral. Perhaps bring these sections together.

I found the discussion of how foodbanks have changed the way they work in response to COVID19 to be a little totalising. Following the transition period in the last month, some Trussell Trust distribution centres have informally adopted direct access, while some independents have adopted referral systems for the first time. Including the ways in which volunteers and distribution centres are doing things differently is important for the section on political and ethical debates on food charity. For example, the paper did not discuss how food parcels made by foodbank volunteers are now distributed to social services and council hubs to bypass the need for vouchers and ease the physical and bureaucratic burden on individuals to travel to the foodbank.

On page 7 the paper states that 'instead of being invited into a building, service users are given a pre-packed food bank parcel, often at the threshold or delivered directly to their home (Trussell Trust, 2020c).' From my experience this is not the case in every foodbank. This is an example where the tone of discussion needs to reflect the ambiguity and heterogeneity of how foodbanks have responded. Stating that 'Care, sign-posting, and choice is removed from the interaction' (page 7) is another example where I felt the claim is overstated. Although this is anecdotal evidence, people have come a Cardiff foodbank distribution centre requesting help with ringing utility companies, social services, and organising longer-term support from the council for those eligible. The volunteers who had experience in doing this were able to advise/signpost/ring on their behalf (if requested) while keeping social distance. Some food banks and volunteers are trying to find ways of ensuring dignity in the way they communicate social distancing rules and by offering choice even in the pre-made food parcels. Equally, the additional 'policing' of the movement of people (where to stand, sit, hand over the voucher) can be 'doubly stigmatising'. Such rules, if conveyed insensitively, are likely to exacerbate feelings of shame for people who are using the foodbank for the first time. While this is highly contingent on layout and volunteers in each distribution centre, the experience is far more ambivalent than suggested here. Even so, this underlines the importance for the policy recommendations made in the paper (e.g. cash payments, cutting the 5 week for Universal Credit, increase Child Benefit).

Fourthly, there are several points where there is opportunity to provide detailed evidence and citation. These sources were not available at time of publication but provide additional evidence on the challenges of COVID19 on the food system and household food insecurity, and responses to it:

FAO (2020) Urban food systems and COVID-19: The role of cities and local governments in responding to the emergency ${ }^{1}$.

Loopstra R (2020) Vulnerability to food insecurity since the COVID-19 lockdown².

Lang T (2020) Feeding Britain. Penguin ${ }^{3}$.

The critique of foodbank statistics as partial indication of household food insecurity is well established. A brief acknowledgement of this would suffice and would make space for the COVID 
discussion. The paper cites Cipriani (2020) as evidence for sharp increases in demand for food in foodbanks. Since publication of this paper, is there additional evidence to give a sense of the scale and significance of increased food bank usage?

Alongside the discussion of panic buying and stockpiling, the authors might want to include how the just-in-time food system was disrupted by 'less spectacular' practices such as changing food consumption habits ('eating in') and shopping habits (weekly shop).

In discussing 'the empirical and ethical implications of Covid-19 for socioeconomic inequalities in access to food in the UK' the authors could be more explicit with the evidence on gender and race inequalities (see Women's Budget Group (2020) Crises Collides: Women and Covid-19: Examining gender and other equality issues during the Coronavirus outbreak).

On page 4 could you provide updated evidence for the 'increased demands placed on the application system' for Universal Credit? Also can you substantiate the claim made on page 5: 'These volunteers tend to be older (over 70) and some have underlying health conditions; social distancing rules have caused many of these volunteers to stay away from food banks, placing considerable additional pressure on volunteers and staff continuing to distribute food.'

Can the authors specify the contribution being 'academic-practitioners' makes to the paper? It is fairly common for academics especially in this field to have experience as frontline practitioners, policy and advocacy experience. What did the academic-practitioner duality bring to the type of evidence and analysis presented?

Finally, connection between available data and the recommendations. One of the recommendations is for 'hardship funds administered by local authorities, although these funds would need to increase substantially for this to be viable'. While it is not necessary for this paper, it would be useful to include a discussion of the uneven geography of hardship payments made across the UK (evidence of dwindling resources, gatekeeping and reliance on foodbanks). Another recommendation 'that supermarket employees are paid the Real Living Wage, which will increase household income' needs a detailed overview of pay and work conditions in UK supermarkets. More justification is needed of the proposed recommendations, not so much an assessment of alternatives but a defense against likely critiques of each policy intervention.

Finally, I would like to thank the authors for writing a stimulating paper and to emphasise these comments are suggestions rather than a list of necessary revisions.

\section{References}

1. Urban food systems and COVID-19: The role of cities and local governments in responding to the emergency. Food and Agriculture organisation of the United Nations. 2020. Reference Source 2. Loopstra A: Vulnerability to food insecurity since the COVID-19 lockdown. The Food Foundation. 2020. Reference Source

3. Lang T: Feeding Britain. 2020. Reference Source

\section{Is the topic of the opinion article discussed accurately in the context of the current literature?}


Yes

Are all factual statements correct and adequately supported by citations? Partly

Are arguments sufficiently supported by evidence from the published literature? Partly

Are the conclusions drawn balanced and justified on the basis of the presented arguments? Partly

Is the argument information presented in such a way that it can be understood by a nonacademic audience?

Partly

Does the piece present solutions to actual real world challenges?

Partly

Is real-world evidence provided to support any conclusions made?

Partly

Could any solutions being offered be effectively implemented in practice?

Partly

Competing Interests: No competing interests were disclosed.

Reviewer Expertise: Geographies of welfare, food banks and poverty. Austerity and neoliberal governance.

I confirm that I have read this submission and believe that I have an appropriate level of expertise to confirm that it is of an acceptable scientific standard.

Reviewer Report 17 April 2020

https://doi.org/10.21956/emeraldopenres.14610.r26709

(C) 2020 Holt D. This is an open access peer review report distributed under the terms of the Creative Commons Attribution License, which permits unrestricted use, distribution, and reproduction in any medium, provided the original work is properly cited.

\section{Diane Holt}

University of Leeds, Leeds, United Kingdom

The start of this paper presents a useful summary of the (current) emergency measures put into place for income loss related to Covid-19 and an introduction to some of the issues facing the UK food supply system from the perspective of the most vulnerable in our society; those reliant of 
food banks and/or on lower incomes.

Its strength lies in the authors' focus on those in the UK relying on the food bank system and the exacerbation of their vulnerabilities (and those who will need to now access these resources) in this Covid-19 crisis. This nuanced exploration considers differences between those independent food banks and those corporate sponsors and presents a useful and timely overview of their emerging challenges. The blend of practitioners and academics who authored this paper allow us to see some of the aspects of the food bank challenges that might be hidden from view and that I hadn't considered previously - such as the difficulties with volunteers who tend to be older and isolating. The paper provides an insightful overview of the different food bank types and the partnerships underpinning them. The recommendations presented focus on some of the initiatives that might support the clients of these food banks

Recognising this is a paper is written in response to an ongoing and shifting crisis it thus provides a useful and timely introduction for readers. Where I would have liked to see more was on some of the more localised responses that seem to be emerging that are driven not by food banks themselves but by other routes to get food to vulnerable households. Good examples are some of the ad hoc initiatives emerging at a micro-local level for instance in schools who are delivering food to households of children with free school meals, and the role of other local actors such as local food retailers rather than the big supermarkets.

There is also, perhaps not unsurprisingly, little recognition, of some of the supply issues impacting local producers who might need new payments terms, or are struggling themselves due to supply chain disruptions at second and third tier and those (like those supplying flowers) who have had their contracts cancelled as the product ranges narrow in stores in order to address the increased demand for staple products. There are also interesting shifts in some business models of food distributors who, unable to supply to hotels and restaurants, are shifting into a direct consumer market away from wholesale. They may have a role to play in reaching the most vulnerable in communities given their localised focus.

Having spent time working within producer communities in sub-Saharan Africa and seen the global food supply chain 'in action' I recognise the vulnerabilities of this system and the communities that grow some of our imports in the developing world. This is mentioned but not developed further in this paper.

The section on supermarket and retailer responses also seems a little underdeveloped. I know for instance that Sainsburys (as others) are initiating processes to deliver to vulnerable households. There are rapid innovations occurring in the UK food supply system that are happening in real time that may date this paper.

Thus I see this as a timely (and of its time) interesting read. Living through food scarcities, supermarket queues, and trying to order for vulnerable family members the UK food system is very much on my mind at present. Therefore, I do see this as a useful and valuable addition to our knowledge base and a paper that provide some insightful contributions. I would like to see in future work a more longitudinal focus that tracks what has happened and the aftermath

\section{Is the topic of the opinion article discussed accurately in the context of the current literature?}


Yes

Are all factual statements correct and adequately supported by citations?

Yes

Are arguments sufficiently supported by evidence from the published literature?

Yes

Are the conclusions drawn balanced and justified on the basis of the presented arguments? Yes

Is the argument information presented in such a way that it can be understood by a nonacademic audience?

Yes

Does the piece present solutions to actual real world challenges?

Yes

Is real-world evidence provided to support any conclusions made?

Yes

Could any solutions being offered be effectively implemented in practice?

Yes

Competing Interests: No competing interests were disclosed.

Reviewer Expertise: Informal economy supply chains, social enterprise, green supply chains, producer communities, sustainable development

I confirm that I have read this submission and believe that I have an appropriate level of expertise to confirm that it is of an acceptable scientific standard.

Reviewer Report 14 April 2020

https://doi.org/10.21956/emeraldopenres.14610.r26712

(c) 2020 Murdock A. This is an open access peer review report distributed under the terms of the Creative Commons Attribution License, which permits unrestricted use, distribution, and reproduction in any medium, provided the original work is properly cited.

\section{Alex Murdock}

London South Bank University, London, United Kingdom

The article is about a fast moving situation and naturally reflects the situation at the time of writing. The academic sources are all fine and appropriate but I would gently suggest some reconsideration as to whether to include reference to the following (which would not be found in 
'academic ' literature but rather in contemporary 'grey' literature accounts):

1. The challenge of self isolation of the 'older and vulnerable' represents a major challenge to food banks in terms of their volunteer demographic. This has featured in recent accounts and is reflected (online) by the number of Trussell trust food banks shown as closed; It is a moving target though which may have been partly addressed by new and less vulnerable volunteers... It is NOT just about the food.

2. There is significant evidence of emerging partnerships and innovative responses to food issues in COVID - many of these are local ( Food Bikers in Cornwall for example) - Crisis sometimes generates solutions.

3. It terms of UK food insecurity the perceived threat of no migrant workers to gather crops may be resolved by an influx of domestic workers - some laid off by COVID (see the HOPS site which is no longer accepting applications until May due to an apparent surplus of offered labour. However this is a 'moving target' - see Metro link below ${ }^{1}$

Factually the piece is well written and paints a good picture with strong analysis... I only query whether it misses some of the more recent developments. For example Morrisons have reportedly given $£ 10 \mathrm{M}$ to the food banks... possibly one of the largest single money donations in UK food bank history?? This was a direct result of COVID - it is over $£ 20 \mathrm{~K}$ per Trussell trust food bank by my rough estimate? ${ }^{2}$.

\section{References}

1. Courtney-Guy S: UK facing food shortages unless more people take jobs on farms. Reference Source

2. Smithers R: Morrisons gives food banks $£ 10 \mathrm{~m}$ during coronavirus outbreak. Reference Source

Is the topic of the opinion article discussed accurately in the context of the current literature?

Partly

Are all factual statements correct and adequately supported by citations? Yes

Are arguments sufficiently supported by evidence from the published literature? Yes

Are the conclusions drawn balanced and justified on the basis of the presented arguments? Yes

Is the argument information presented in such a way that it can be understood by a nonacademic audience?

Yes

Does the piece present solutions to actual real world challenges?

Yes

Is real-world evidence provided to support any conclusions made? 
Yes

Could any solutions being offered be effectively implemented in practice?

Yes

Competing Interests: No competing interests were disclosed.

Reviewer Expertise: Food Bank and Food Insecurity, Social Innovation, Active Ageing

I confirm that I have read this submission and believe that I have an appropriate level of expertise to confirm that it is of an acceptable scientific standard.

Reviewer Report 07 April 2020

https://doi.org/10.21956/emeraldopenres.14610.r26710

(C) 2020 Loopstra R. This is an open access peer review report distributed under the terms of the Creative Commons Attribution License, which permits unrestricted use, distribution, and reproduction in any medium, provided the original work is properly cited.

\section{Rachel Loopstra}

Department of Nutritional Sciences, Faculty of Life Sciences and Medicine, King's College London, London, United Kingdom

It is excellent to see to this reflective and timely piece on the impacts of the COVID-19 crisis on food insecurity, food aid systems, and food systems more broadly. The authors are well placed to offer their perspectives and comments on these events and outline their reasons for doing so now, at this moment (or the moment one week ago), to chronicle events as they happen. As the situation evolves, new commentaries will be appropriate, but to observe and comment on multifaceted repercussions of the COVID-10 as they happen is also important as they have the opportunity to shape the response in the future, potentially even in the very short term. Important issues are discussed throughout the article, and juxtaposing vulnerability in food supply systems alongside issues in food banks and how the two are connected is useful.

Below I offer some recommendations for how points could be strengthened by making reference to evidence and sources, but also pointing out where evidence is scant and anecdotal; a critical part of this story is that food banks and other forms of food aid are largely left to operate without scrutiny or evidence of their actual ability to ensure that people receive food when they are faced with food insecurity.

Key weaknesses in the operations of food banks exposed by the COVID-19 crisis are discussed, but it might be useful to point out the research that has documented and discussed different elements of fragility in the system before this crisis. It has been a long-standing concern among researchers that food charity cannot and should not be relied upon to provide food to people at risk of food insecurity. This is because the system itself cannot provide "security" given the system is so contingent on voluntary donations and volunteer labour. Instances of food banks running low on food and at times, having to cut down on the size of food parcels or turn people away have 
been documented before. It would also be useful to more explicitly outline what food bank closures and limited food supplies will mean for people who have come seeking help from food banks: what might it mean for someone who is facing not having enough food to then not be able to access their local food bank? Some references to incorporate on documented weaknesses in food bank systems:

Tarasuk, V., Dachner, N., Hamelin, A. et al. A survey of food bank operations in five Canadian cities. BMC Public Health 14, $1234(2014)^{1}$.

Loopstra, R., Lambie-Mumford, H. \& Fledderjohann, J. Food bank operational characteristics and rates of food bank use across Britain. BMC Public Health 19, 561 (2019)².

Some caution is needed in reporting on the effects of Covid-19. It would be useful to see caveats such as "media reports from talking to frontline food bank managers and volunteers found..." with reference to comments about the increase in food bank demand and the reasons for it. These observations from individual food banks may bear out in data from food banks, but without systematic collection and reporting on this, it is important to note that this is anecdotal evidence, likely from food banks experiencing the greatest increases in demand.

With reference to the Government's CJRS, it might be useful to also highlight that $80 \%$ of wages will be paid up to $£ 2,500$ before tax. This means people earning over $£ 30,000$ will have relatively higher reductions. While it is possible that they are a less economically vulnerable group, this is highly dependent on how many dependents they have in their household and where they live. They may also have higher fixed costs, such as mortgage/rent payments, house insurance etc. Comments on "Emerging fragilities within the UK food aid system" could be better supported by references and more description. For those not familiar with FareShare, it would be useful to describe how they operate and to include reference to their website. In terms of how food banks work, you could include a reference to the Trussell Trust's website and also to our survey of independent food banks in England, which documents sources of food donations ( https://www.foodaidnetwork.org.uk/independent-food-bank-survey).

It is good to highlight the level of debt that the poorest have, but also their lack of savings to withstand financial shocks. The ONS also reports some statistics on this here:

https://www.ons.gov.uk/peoplepopulationandcommunity/healthandsocialcare/conditionsanddiseases/articles/ 03-26.

The variation between the extent of food bank use and numbers experiencing food insecurity are also sharply revealed by the estimates of number of people who are food insecure and estimated number of individuals who use food banks. See for example Loopstra et al. (2019) ${ }^{3}$ where estimated number of adults using Trussell Trust food banks was 321,599 adults in 2016-17 and estimated number food insecure based on the Food and You 2016 data was 10.2 million, including marginal food insecurity. Even if food bank use figures were doubled to account for independent food bank use, there is a wide discrepancy. The more recent State of Hunger report also provides an estimate of the discrepancy between food insecurity and food bank use figures.

Loopstra R, Reeves A, Tarasuk VThe rise of hunger among low-income households: an analysis of the risks of food insecurity between 2004 and 2016 in a population-based study of UK adults] Epidemiol Community Health 2019;73:668-673³.

https://www.trusselltrust.org/state-of-hunger/

Reference is made to a survey of households conducted in York - "20\% of households reporting food insecurity had ever used a food bank", but as this survey was conducted among households with children in primary school, a more refined description of this survey should be provided. 
Single individuals, particularly men, are an important demographic in food banks, thus, the discrepancy between food bank use and food insecurity among households with children may not be the same for other household demographics.

When discussing the distribution of food insecurity in the population, it might be useful to reference our multi-variate analysis of the 2016 Food and You data (Loopstra et al. 2019, ibid). It highlights which socio-economic characteristics are independently associated with higher odds of food insecurity, but also the characteristics associated with severe food insecurity in particular. Very relevant to note here is how people with health conditions, and particularly those for whom their conditions limit their daily activities (i.e. those by definition with a disability) are at higher risk of food insecurity.

The meaning of this statement is not clear to me: "Sustained and, particularly, hidden food insecurity is, thus, both an individual and a societal issue." First, I would argue that no one should ever have to go without food, so whether sustained or a single episode, food insecurity is a societal issue. Second, hidden food insecurity is certainly important, but in the context of the scale of the problem now being tracked beyond food bank use statistics through the Food and You survey and monitoring in Scotland, as well as forthcoming monitoring through the Family Resources Survey, it isn't clear what hidden food insecurity refers to. Is this among people not captured in household surveys (importantly here, people who are homeless and people who are institutionalised) or among people who do not respond to household surveys, or among people who do not give honest responses?

The discussion of the impacts of school closures on access to food among Free School Meal recipients is useful but focuses on the experiences of children who are eligible to receive them or who may newly become eligible to receive them on account of unemployment or reductions in income. But here, it would be useful to highlight concerns about eligibility: how low the income threshold is for working families (for example, see https://cpag.org.uk/welfarerights/resources/article/universal-credit-and-free-school-meals) and families with no recourse to public funds who have newly become unemployed who are not eligible.

With reference to growing vulnerability on account of self-isolation rules, distinguishing between vulnerability to food insecurity arising from a lack of finances from that arising from a lack of physical access to food would be useful here. Food banks focus on reaching people affected by the former. For example, on the Trussell Trust website, this statement can be found: "If you can afford food or aren't in financial difficulty but can't get to the shops because you're self-isolating, you should contact your local council or Citizens Advice for support. Food banks can only help people who don't have enough money for food and many are having to run reduced services in order to do this safely during the outbreak, so they're not best placed to deliver to you." (https://www.trusselltrust.org/coronavirus-food-banks/faqs/\#1585815322735-9695c857-a1d6) Discussion of local government and central government responses- and their limitations (i.e. only a fraction of people at risk of severe illness from coronavirus on account of an underlying specific health condition have been identified by government) would be useful. Whilst schemes suggest the government is showing responsibility for vulnerability arising from health issues, they are likely not going far enough, and they are relying (once again) on charities to fill the gap, even though it is clear that some charities, as in The Trussell Trust's statement, do not feel it appropriate for them to be charged with this task. 
A question is raised: "can a clear distinction be made between individuals seeking food support due to income and those requesting assistance due to health?" But clearly a distinction can be made, even though many people who do not have sufficient incomes also have health conditions. If someone has money in the bank, but cannot use these finances to access food because they cannot get to shops or get a food delivery, this is a problem of physical access. Others have no money in the bank and also cannot go out to shops or get a food delivery. The former group also likely do not have the same array of other disadvantages as the latter such as lack of social network, lack of money for phones or internet, risk of not being able to make housing payments and other bills, etc. given how people in poverty experience multiple disadvantages.

Local Government Resilience Forums are mentioned, but not defined. As above, it would be useful to see discussion on how governments are responding to food access for those being told to selfisolate for 12 weeks, as this highlights where responsibility is being taken and reveals gaps where people are being left without support.

The last paragraph on page 6 needs reference to sources. What is the reference for " $40 \%$ of independent food banks operate on an open-access basis"? and what is the source of evidence that independent food banks are receiving clients who have been unable to receive a referral to a Trussell Trust food bank? (and is this a new phenomenon or could this not always be the case?) When referencing the study of independent food banks (Loopstra R, Goodwin S, Goldberg B, et al.: A survey of food banks operating independently of The Trussell Trust food bank network. 2019.), it is important to point out that this was only a survey of independent food banks operating in England.

The recommendations, whilst all very important, do not necessarily arise from the evidence reviewed in the body of the paper. For example, more could have been said about the demographic of people who use food banks and who will now also be left insufficiently protected by government assistance. This discussion necessitates discussion of the rates of welfare benefits in the body of the paper. The recently announced increase in universal cred it also begs a question about whether people who currently are using food banks because universal credit is insufficient to cover their basic needs will now be at lower risk of food insecurity.

Another important issue is the lack of financial resilience built into the social security system. The barely enough (and often not enough) levels of assistance (emulated by calculations of Minimum Income Standards: https://www.jrf.org.uk/report/minimum-income-standard-uk-2019) mean that many people living on these incomes cannot save and therefore have no financial buffer when exposed to shocks.

Discussion of wages of supermarket staff are important, but it is not evidenced in the paper that they are not paid the Real Living Wage already. What proportion of supermarkets do not pay this? It is not clear why supermarkets would he charged with implementing a public health initiative akin to Healthy Start. Why would this not be initiated by government and available across supermarkets?

The recommendation that supermarkets continue to pledge food donations to food charities seems out of line with discussion in the paper about concerns about the corporatisation of food and reliance on food aid systems in general. Again, it is not clear why supermarkets are being charged with this. 
Under recommendations for "Emergency Food Provision", it is recommended that cash grants be provided. Who these should be provided to at this time is not explained. How these would work for people facing self-isolation is also not clear. This section would be enhanced by delineating between recommendations to prevent food insecurity arising from the financial shocks caused by the crisis and the food insecurity arising from a lack of physical access to food. Reiterating why it is important that no one must rely on food banks at this time would be useful.

\section{References}

1. Tarasuk V, Dachner N, Hamelin AM, Ostry A, et al.: A survey of food bank operations in five Canadian cities.BMC Public Health. 2014; 14: 1234 PubMed Abstract | Publisher Full Text

2. Loopstra R, Lambie-Mumford H, Fledderjohann J: Food bank operational characteristics and rates of food bank use across Britain.BMC Public Health. 2019; 19 (1): 561 PubMed Abstract | Publisher Full Text

3. Loopstra R, Reeves A, Tarasuk V: The rise of hunger among low-income households: an analysis of the risks of food insecurity between 2004 and 2016 in a population-based study of UK adults.J Epidemiol Community Health. 2019; 73 (7): 668-673 PubMed Abstract | Publisher Full Text

Is the topic of the opinion article discussed accurately in the context of the current literature?

Yes

Are all factual statements correct and adequately supported by citations? Partly

Are arguments sufficiently supported by evidence from the published literature? Partly

Are the conclusions drawn balanced and justified on the basis of the presented arguments? Partly

Is the argument information presented in such a way that it can be understood by a nonacademic audience?

Partly

Does the piece present solutions to actual real world challenges?

Partly

Is real-world evidence provided to support any conclusions made?

Partly

Could any solutions being offered be effectively implemented in practice? Partly

Competing Interests: No competing interests were disclosed.

I confirm that I have read this submission and believe that I have an appropriate level of 


\section{expertise to confirm that it is of an acceptable scientific standard, however I have} significant reservations, as outlined above.

Reviewer Report 06 April 2020

https://doi.org/10.21956/emeraldopenres.14610.r26713

(C) 2020 Jackson P. This is an open access peer review report distributed under the terms of the Creative Commons Attribution License, which permits unrestricted use, distribution, and reproduction in any medium, provided the original work is properly cited.

\section{Peter Jackson}

Department of Geography, University of Sheffield, Sheffield, United Kingdom

This is an interesting and timely paper that reviews the way the current Coronavirus pandemic (COVID-19) has drawn attention to, and exacerbated, inequalities in the UK food system. The paper has a particular focus on those who rely on foodbanks and other forms of 'emergency' food aid. It raises interesting questions about the way social scientists can respond to ongoing crises, where reliable data are not readily available. This is particularly striking in relation to the evidence on which the authors base their Recommendations where the data is, necessarily, incomplete and of inconsistent quality.

The authors outline the way COVID-19 has drawn attention to the fragility of the food supply chain. This has been both short-term (in response to panic buying) and longer-term (in relation to our reliance on imported food). A useful further reference here would have been Tim Lang's recent book on Feeding Britain (2020).

The authors claim to have a 'unique perspective' on these issues because of their combined experience of food policy, research and advocacy. I thought this was somewhat overplayed and would be true of many research teams and co-authored papers. More specifically, they use their expertise 'to chronicle and assess' the available evidence (p.3). More could have been said about the fragmentary nature of the evidence and the challenges of assessing a situation that is changing on a daily basis.

The paper was written within the first few weeks of the COVID-19 pandemic affecting the UK. This gives it an urgency, reflecting on issues as they evolve in more-or-less 'real time'. It also poses problems in terms of the evidence on which the paper is based including sources (newspapers, grey literature) which do not meet the highest (peer reviewed) standards of social science evidence. Similarly, phrases like 'in recent days' are unhelpful in a rapidly evolving context and would be better replaced with a specific date.

While the authors provide a good review of the challenges facing people on low-incomes, especially those requiring access to Universal Credit, more could have been said about the way current policies such as social distancing and self-isolation have exacerbated problems of accessing safe, nutritious food.

The question of 'vulnerability' could also have received more attention. It wasn't clear whether or 
not the authors subscribe to the conventional view that people are vulnerable because of their demographic or medical status (as elderly, pregnant or with an underlying condition). This definition has been challenged (in the context of foodborne disease) where an alternative definition seems preferable, based on a 'pathways and practices' approach. Rather than seeing all elderly people as equally at risk, for example, this approach focuses on the pathways and practices that increase their vulnerability. I wondered if this approach (outlined in Critical Public Health, 2018) might also be relevant here?

The most problematic part of the paper, in my view, is the way the Recommendations are underpinned by appropriate evidence. While I would personally support supermarket workers being paid a Real Living Wage or the abolition of the 5-week wait for Universal Credit or price promotions on fruit and vegetables, one would (in other circumstances) expect to see a more robust review of the pros and cons of these policies. Would there be a sufficient supply of fruit and veg to meet the likely increased demand? What bureaucratic and other challenges would need to be addressed by an immediate switch in eligibility rules? These are just examples of the problematic link between evidence and policy prescription that arise in 'emergency' conditions such as we are currently facing and the authors may argue that it is preferable to base policy shifts on incomplete evidence if the alternative is worse in terms of its adverse effects on those already most 'vulnerable'. But these issues demand further exploration in my view.

Finally, there are some minor editorial issues that should be addressed in any future revisions of the paper: 'mitigate against' is ungrammatical (not to be confused with 'militates against'). The phrase is used repeatedly throughout the paper and should simply be 'mitigate'. The References are not in correct alphabetical order, and the phrase 'pregnant mothers' (page 8) should be 'pregnant women'.

Is the topic of the opinion article discussed accurately in the context of the current literature?

Yes

Are all factual statements correct and adequately supported by citations? Yes

Are arguments sufficiently supported by evidence from the published literature? Partly

Are the conclusions drawn balanced and justified on the basis of the presented arguments? Yes

Is the argument information presented in such a way that it can be understood by a nonacademic audience?

Yes

Does the piece present solutions to actual real world challenges?

Yes

Is real-world evidence provided to support any conclusions made? 
Yes

Could any solutions being offered be effectively implemented in practice?

Yes

Competing Interests: No competing interests were disclosed.

Reviewer Expertise: Food security and sustainability particularly in relation to consumption issues

I confirm that I have read this submission and believe that I have an appropriate level of expertise to confirm that it is of an acceptable scientific standard, however I have significant reservations, as outlined above.

\section{Comments on this article}

\section{Version 1}

Author Response 04 Apr 2020

Bob Doherty, University of York, UK, York, United Kingdom

Hi Dominic, You make a very good point we are hearing of new ways in the UK and right across the world of getting food to vulnerable groups. We are using various networks to capture this and we plan to document these also in the next few weeks. Any information would be much appreciated. Many Thanks, Bob

Competing Interests: No competing interests were disclosed.

\section{Reader Comment 03 Apr 2020}

dominic moran, Edinburgh University, Ednburgh, United Kingdom

Interesting article, but I wonder whether some of the food bank shortfall is being offset by a lot of informal emergency feeding that is going on. Anecdotally I know of several restaurants that are furloughing staff and distributing cooked stock to vulnerable communities. I'm not aware that a lot of this is being documented.

Competing Interests: no competing interest 